\title{
Update of Human Infections Caused by Cryptosporidium spp. and Cystoisospora belli, Honduras
}

\section{Rina Girard Kaminsky ${ }^{1^{*}}$ and Selvin Zacarías Reyes-García ${ }^{2}$}

${ }^{1}$ Pediatric Department, School of Medical Sciences, National Autonomous University of Honduras and Parasitology Service, University Hospital, Honduras

${ }^{2}$ Department of Morphological Sciences, School of Medical Sciences, National Autonomous University of Honduras, Tegucigalpa, Honduras

"Corresponding author: Rina Girard Kaminsky, Pediatric Department, School of Medical Sciences, National Autonomous University of Honduras and Parasitology Service, Department of Clinical Laboratory, University Hospital, Honduras, Tel: +1 5042238 8851; E-mail: camilaestela12@yahoo.com

Received date: July 10, 2017; Accepted date: July 21, 2017; Published date: July 26, 2017

Copyright: (2017 Kaminsky RG, et al. This is an open-access article distributed under the terms of the Creative Commons Attribution License, which permits unrestricted use, distribution, and reproduction in any medium, provided the original author and source are credited.

\begin{abstract}
Background: Cryptosporidium spp., and Cystoisospora belli are two intestinal apicomplexa protozoa associated with diarrhea and malnutrition in individuals of different ages and immune competency.

Objectives: Update diagnosis of infection with either Apicomplexa species, twelve years cumulative results at the University Hospital, Honduras.

Methodology: Observational, non-interventional revision of stool examination results, in the diagnosis of intestinal apicomplexa oocysts as identified in fixed and stained smears by the modified carbolfuchsin method (MAF).

Results: Of 42,935 stool samples received during a 12 year period, $30.4 \%(13,041)$ were MAF stained and examined, of which $8,705(20.3 \%)$ came from children 0 to 5 years old. For $C$. belli infections, 89 of a total of 109 $(81.6 \%)$ cases were identified in patients 21 years old or older $(p=0.001) ; 67.2 \%$ of the stools were diarrheic or liquid. In 19 individuals the excretion of $C$. belli oocytes persisted several months to a year despite treatment with trimetroprim sulfametoxazol. Age distribution of a total of $202(1.5 \%)$ cryptosporidiasis cases showed two peaks: one in children 0 to 5 years old $(56.4 \%)$ and the second in individuals 21 years old or older $(35.1 \%)(p=0.001)$. The highest proportion of cryptosporidiasis cases was diagnosed in the age group 0 to 35 months old (91/114, 79.8\%). No statistical differences were found in cryptosporidiasis and seasonality, stool consistency or sex. Strongyloides stercoralis larvae, Blastocystis spp., leukocytes and mucus were main additional findings. It appears that no other laboratory in the country diagnoses these parasite infections routinely.
\end{abstract}

Conclusion: It was evident that these apicomplexa parasites are important etiologic agents of diarrheal disease, both in children and in immunocompromised individuals. Cryptosporidiasis burden of disease was evident in children seeking hospital care. Responsible commitment to tackling interdisciplinary research in Honduras regarding these parasites in particular is required.

Keywords: AIDS patients; Cryptosporidium spp.; Cystoisospora belli; Honduras; Intestinal apicomplexa; Parasitology diagnosis

\section{Introduction}

Cryptosporidium spp. and Cystoisospora belli (formerly known as Isospora belli) are tissue-dwelling, oocyte-forming parasites, having been reported in individuals from tropical, subtropical and temperate regions, although differing in their epidemiologic characteristics [1-6]. Cryptosporidium is now recognized as a very common human pathogen worldwide affecting disproportionately young children in developing countries; the recent Global Enteric Multicenter Study (GEMS) study of children under 5 years old in seven developing countries of Asia and Africa brought attention to the frequency of moderate to severe diarrhea caused by Cryptosporidium and that such diarrhea "is a high risk factor for linear growth faltering and death" [3]. Cystoisospora belli is an uncommon intestinal disease in children or adolescents; in immunocompetent individuals it has a mild and transient course. In the presence of immunocompromise, however, the disease may be chronic, severe and life threatening causing chronic diarrhea that could progress to a debilitating status or even death [5-7].

Honduras is the third poorest country in Latin America and the Caribbean; diarrhea in children under 5 years old is an important cause of illness and death, resulting in more than 200,000 consultations in public clinics and hospitals, 4,000 hospitalizations and 1,000 deaths per year [8]. The HIV/AIDS pandemic is a serious and growing threat for the country; since its first diagnosed case in 1985, there have been a total of 32, $826 \mathrm{HIV}$ positive cases: 22, 827 AIDS cases, and 9, $999 \mathrm{HIV}$ asymptomatic infections [9]. Limited parasitology studies at the UH in these patients demonstrated $10 / 80 \quad(12.5 \%)$ to $9 / 56 \quad(16.1 \%)$ Cryptosporidium infection and $12 / 80$ (15\%) to $17 / 56$ (30.4\%) C. belli infections in hospitalized AIDS patients [10,11].

Although both Cryptosporidium spp. and C. belli oocytes have been recognized in children with diarrheal disease and in AIDS hospital based patients in Honduras [12] with clinical consequences, neither laboratory diagnosis is a notifiable disease to the Ministry of Health in Honduras. The aim of this study was to obtain, analyze and make 
Page 2 of 9

available to the scientific community twelve years cumulative results on Cryptosporidium spp. and C. belli infections as diagnosed at the Parasitology Service (PS), Department of Clinical Laboratory, University Hospital (UH), Honduras. This information should be useful to practicing clinicians, as well as to stimulate interest for much needed research. It also brings attention that in countries with limited resources a well-kept registry book in laboratories manned by welltrained supervised personnel, may be a source of useful and low cost information where community or field studies are few or lacking.

\section{Materials and Methods}

\section{Study site}

As described previously $[13,14]$, the University Hospital is a tertiary care facility in the capital city, Tegucigalpa; a referral hospital for the country serving a poverty or below poverty line population and a teaching hospital adjacent to the School of Medical Sciences from the National Autonomous University of Honduras. The Parasitology Service (PS) serves this 1050 bed-capacity hospital during the morning shift (7:00 a.m. to 2:00 p.m.) daily from Monday to Friday and is composed of a diagnostic section for intestinal parasites and another one for the diagnosis of blood and tissue parasites (malaria, Leishmania spp., Trypanosoma cruzi, Pneumocystis spp.). The afternoon and night shifts are not included in this study since they do not fall under the quality control of the Parasitology Service supervision.

\section{Data retrieval}

This is an observational, descriptive, non-interventional study revising the laboratory registry book for twelve years (2002-2013) of parasitology data on two apicomplexan parasites, Cryptosporidium spp. and C. belli, identified during routine coproparasitoscopic exams. The protocol of the study was revised and approved by competent authorities, considering that it did not involve human subjects and there was no direct contact with patients at any time, posing no potential risk or threat to their health or wellbeing. The data confidentiality was preserved according to the Helsinki Declaration of Bioethics; the registry books are kept in the PS for professional use exclusively. The results obtained from the data retrieval were regarded as ancillary to clinical differential diagnoses applicable to the needs of the local population consulting at this facility.

The data supporting the findings reported here were retrieved manually from the laboratory book and annotated in a specially designed survey format; at present, the PS does not count with machine readable prints. It included total monthly and yearly stool examinations; the monthly macroscopic and microscopic results of general parasitology and MAF; and age and sex as annotated from the stool form request. No other data are usually available from the stool request form, except whether it is an outpatient or an in-ward request. No controls were included, i.e., results of stool exams not stained by the modified acid fast carbolfuchsin stain or negative results for the presence of apicomplexan oocysts. Sporadically, sputum samples were received for diagnosis of Pneumocystis infections in adult immunocompromised patients; a MAF stained smear was always included for potential Cryptosporidium oocysts identification.

\section{Laboratory methods}

Methodological standards governing the parasitology laboratory protocols have been in place since $1990[12,14]$ to confirm the presence or absence of intestinal parasites or their products of reproduction (trophozoites, cysts, oocysts, eggs, larvae), leukocytes and CharcotLeyden crystals. The routine methodology includes registering macroscopic stool characteristics such as consistency, presence of mucus and/or blood, adult parasites or segments, followed by microscopic stool examination by a direct smear method using physiologic saline solution and a smear in Lugol solution [15]. Oil immersion is used for better visualization of speciation morphology of protozoa cysts and/or trophozoites in the Lugol suspension and to examine stained slides. Stools from any patient 5 years old or less, as those from physician requests, are routinely examined by a modified acid fast carbolfuchsin stain (MAF) for apicomplexan oocyst differentiation $[15,16]$. Additional methods include a flotation method (zinc sulphate and/or Sheather) to recover protozoa cysts, a modified Baermann method for the recovery of Strongyloides larvae, and a Kato thick smear as a concentration method for diagnosis of light helminth infections including Taenia eggs; these methods are performed usually in response to physician request $[15,16]$. Only one stool sample per person is routinely received for examination; some cystoisosporiasis patients had repeated stool examination requests over a period of several months; care was taken to include them only once in the total count for cystoisosporiasis, and results of that group are presented in a separate table.

\section{Statistical analyses}

Statistical analyses were performed using SPSS v.21.0 (IBM Corp., Armonk, NY, USA). Chi-square tests were used for association of pathogens and age and sex groups, as well as yearly comparisons. Analyses of variance were performed using Kruskal-Wallis nonparametric test and pairwise multiple comparisons were performed by post-hoc Dunn's test. $\mathrm{P}$ values of $<0.05$ were considered statistically significant.

\section{Results}

A detailed recount on the total stool examinations, percentage of stool exams requested for the age group 0 to 5 years old and the percentage of MAF microscopically examined during twelve years are presented in Table 1 . About one fourth $(8,705 / 42,935 ; 20.3 \%)$ of the stool examination requests came from children 5 years old or less and one third $(30.8 \%)$ of all stool requests was examined by the modified acid fast carbolfuchsin method. Oocysts of Cryptosporidium were identified in MAF by their morphology, rounded or slightly oval, measuring no more than $6 \mu \mathrm{m}$ in diameter, staining deep purple on a blue background (Figure 1a). Cystoisospora belli oocysts were unsporulated when passed in the stools, elongated ovoidal in shape, and measuring $25 \mu \mathrm{m}$ to $32 \mu \mathrm{m}$ by $12 \mu \mathrm{m}$ to $19 \mu \mathrm{m}$ (Figure $1 \mathrm{~b}$ ). Some C. belli oocysts were allowed to continue to develop in the laboratory, resulting in oocysts with two sporocysts containing four sporozoites each (Figure 1c). In stained preparations, the oocysts had a characteristic appearance (Figure 1d). 
Citation: Kaminsky RG, Garcia SZR (2017) Update of Human Infections Caused by Cryptosporidium spp. and Cystoisospora belli, Honduras.

Page 3 of 9

\begin{tabular}{|c|c|c|c|c|c|c|c|c|}
\hline \multirow{4}{*}{ Year } & \multirow{4}{*}{$\begin{array}{l}\text { Total stool } \\
\text { exams }\end{array}$} & \multirow{4}{*}{$\begin{array}{l}\text { Total exams } \\
\text { in ages } \\
0-5 \text { y (\%) }\end{array}$} & \multirow{4}{*}{$\begin{array}{l}\text { Total modified } \\
\text { acid fast stain }(\%)\end{array}$} & \multicolumn{5}{|c|}{ Stool consistency, all age groups } \\
\hline & & & & \multicolumn{5}{|c|}{ Cryptosporidium/Cystoisospora belli } \\
\hline & & & & \multicolumn{2}{|c|}{$(n=202)$} & \multicolumn{2}{|c|}{$(n=109)$} & \multirow[b]{2}{*}{ ND C } \\
\hline & & & & Frm & Sft & Drr & Lqd & \\
\hline 2002 & 4392 & $744(17.0)$ & $894(20.3)$ & $4 / 2$ & $4 / 4$ & $3 / 1$ & $8 / 13$ & \\
\hline 2003 & 3848 & $841(21.9)$ & $1047(27.2)$ & $5 / 3$ & $11 / 2$ & $10 / 0$ & $14 / 10$ & 1 \\
\hline 2004 & 4310 & $799(18.5)$ & $1226(28.4)$ & $4 / 1$ & $6 / 1$ & $6 / 6$ & $5 / 4$ & \\
\hline 2005 & 2878 & $523(18.1)$ & $1226(42.5)$ & $4 / 2$ & $5 / 2$ & $5 / 1$ & $5 / 3$ & 2 \\
\hline 2006 & 3345 & $478(14.2)$ & $864(25.8)$ & $1 / 1$ & $5 / 0$ & $1 / 0$ & $3 / 2$ & \\
\hline 2007 & 3205 & $510(15.9)$ & $852(26.5)$ & $0 / 0$ & $2 / 2$ & $4 / 1$ & $8 / 5$ & \\
\hline 2008 & 2738 & $419(15.3)$ & $763(27.8)$ & $1 / 3$ & $4 / 3$ & $0 / 0$ & $5 / 11$ & \\
\hline 2009 & 2789 & $518(18.6)$ & $904(32.4)$ & $0 / 1$ & $3 / 3$ & $2 / 0$ & $5 / 3$ & \\
\hline 2010 & 3649 & $834(22.9)$ & $1024(28.8)$ & $1 / 2$ & $4 / 2$ & $2 / 0$ & $0 / 6$ & 2 \\
\hline 2011 & 4003 & $977(24.4)$ & $1204(30.0)$ & $0 / 0$ & $3 / 0$ & $2 / 0$ & $6 / 3$ & 1 \\
\hline 2012 & 3900 & $1015(26.0)$ & $1399(35.9)$ & $1 / 0$ & $5 / 0$ & $6 / 0$ & $5 / 2$ & \\
\hline 2013 & 3878 & $1047(26.9)$ & $1638(42.2)$ & $3 / 0$ & $8 / 1$ & $4 / 0$ & $2 / 3$ & 1 \\
\hline Totals (\%) & 42935 & $8705(20.3)$ & $\begin{array}{l}13041 \\
(30.4)\end{array}$ & $24 / 15(11.8 / 12.7)$ & $\begin{array}{l}60 / 20 \\
(29.7 / 16.9)\end{array}$ & $45 / 9(22.7 / 7.6)$ & $66 / 65(32.6 / 59.6)$ & $7(3.4)$ \\
\hline
\end{tabular}

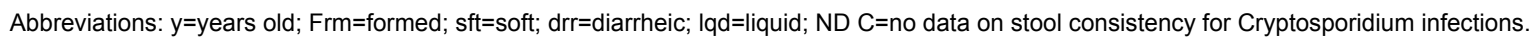

Table 1: Frequency distribution of retrospective laboratory results with totals and percentages of stool exams; total stained smears; stool consistency in Cryptosporidium spp. and Cystoisospora belli infections, Honduras.

There was no particular seasonality identified with Cryptosporidium spp. or $C$. belli infections as diagnosed by month during twelve years. Two hundred and two (1.5\%) Cryptosporidium cases were diagnosed during the elected period for this study. The majority $(114 / 202 ; 56.4 \%)$ of the infections was diagnosed in the age group 0 to 5 years old, and $71 / 202(35.1 \%)$ positive cases were diagnosed in the age group $>21$ years old (Table 2).

An analysis of variance with nonparametric test (Kruskal-Wallis) showed that there was a statistically significant difference between the number of cases and age groups for Cryptosporidium $(\mathrm{H}=24.5$, $\mathrm{p}=0.001)$. Post hoc Dunn test established that this difference was found between groups 0 to 5 years old and 6 to 20 years old and between 6 to 20 years old with the $>21$ years old group. Because Cryptosporidium infections have important health consequences in infants and children less than 5 years old, the age group 0 to 5 years was further subdivided into four age categories (Table 3 ).

The youngest infected child was 2 months old. The highest proportion of cases was diagnosed more frequently in the group 0 to 35 months old $(91 / 114,79.8 \%)$. An analysis of variance showed statistically significant difference among age categories; the Post hoc Dunn test established difference between groups 12-23 months and 24-35 months old $(\mathrm{H}=10.9, \mathrm{p}=0.012)$, the 12-23 months old age category showing the highest incidence of cases $(45 / 114,39.5 \%)$. Microscopic diagnosis of Cryptosporidium oocytes diminished in the age group 6 to 20 years old $(12 / 202,5.9 \%)$, but became more frequently recognized (35.1\%) among young adults and older individuals. Leukocytes (21.4\%), Charcot-Leyden crystals (7.0\%) and mucus (12.9\%) were also reported among the 201 Cryptosporidium infections (data not shown). Stool consistency was recorded as diarrheic or liquid in $54.9 \%$ cryptosporidiasis cases; no estimation of the infection intensity was investigated since the oocytes present in the stained slides were not counted. Cryptosporidium oocysts were found once in the mucus attached to a traqueal tube sent to the laboratory that had been removed from a severely ill child.

Cystoisospora belli oocysts were identified in 109 (0.8\%) MAF preparations (Table 4); more than half (67.2\%) of the stools were of a diarrheic or liquid consistency (Table 1). Significant association of cases by year was found for C. belli infections in 2002 and 2008, with 21 and 18 cases, respectively $\left(\mathrm{x}^{2}=60.465, \mathrm{p}<0.001\right)$ (Table 4$)$. 
Citation: Kaminsky RG, Garcia SZR (2017) Update of Human Infections Caused by Cryptosporidium spp. and Cystoisospora belli, Honduras.

Page 4 of 9

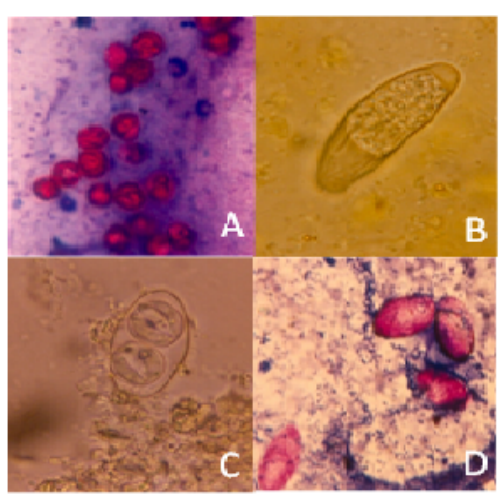

Figure 1: Original microphotographs of microscopic preparations representing different stages of Cryptosporidium spp., and Cystoisospora belli oocytes.

A. Cryptosporidium spp., oocysts, stained smear B. Cystoisospora belli unsporulated oocyst, fresh preparation C. Cystoisospora belli sporulated oocyst, saline smear D. Cystoisospora belli stained smear, oocysts with a characteristic appearance (All 1000X, originals RG Kaminsky).

\begin{tabular}{|c|c|c|c|c|c|}
\hline \multirow{2}{*}{ Year } & \multicolumn{4}{|c|}{ Cryptosporidium by sex and age groups (\%) } & \multirow[t]{2}{*}{ Totals } \\
\hline & $0-5 y$ & $6-20 y$ & $>21 \mathrm{y}$ & Masc/Fem & \\
\hline $2002+$ & $12(63.1)$ & $1(5.3)$ & $5(31.6)$ & $12 / 7$ & 19 \\
\hline 2003+ & $24(60.0)$ & $1(2.5)$ & $13(32.5)$ & $24 / 16$ & $40^{*}$ \\
\hline 2004+ & $9(45.0)$ & $1(4.7)$ & $9(38.0)$ & $15 / 5$ & 20 \\
\hline 2005+ & $13(59.0)$ & $2(9.0)$ & $7(31.8)$ & $7 / 15$ & 22 \\
\hline 2006 & $3(30.0)$ & $2(20.0)$ & $5(50.0)$ & $5 / 5$ & 10 \\
\hline 2007 & $7(50.0)$ & $1(7.1)$ & $6(42.8)$ & $7 / 7$ & 14 \\
\hline 2008++ & $2(20.0)$ & $1(10.0)$ & $7(70.0)$ & $5 / 5$ & 11 \\
\hline 2009 & $5(50.0)$ & $1(10.0)$ & $4(40.0)$ & $5 / 5$ & 10 \\
\hline 2010 & $7(77.7)$ & 0 & $2(22.2)$ & $3 / 6$ & 9 \\
\hline 2011 & $9(75.0)$ & 0 & $3(18.1)$ & $9 / 3$ & 12 \\
\hline 2012 & $11(64.7)$ & $1(5.9)$ & $5(29.4)$ & $11 / 6$ & 17 \\
\hline 2013 & $12(66.6)$ & $1(5.5)$ & $5(27.7)$ & $7 / 11$ & 18 \\
\hline $\begin{array}{l}\text { Totals } \\
\text { (\%) }\end{array}$ & $114(56.4)$ & $12(5.9)$ & $71(35.1)$ & $\begin{array}{l}110 / 91 \\
(54.4 / 45.0)\end{array}$ & $202^{* *}$ \\
\hline
\end{tabular}

+2002 to 2005 a total of 5 patients no age registered; ++2008 one patient no sex registered, thus some columns may not add up.

"Association analysis found significant difference between cases and year in $2003,\left(x^{2}=45.579, p<0.001\right)$.

${ }^{* *}$ Analysis of variance by Kruskal-Wallis test shown statistical difference among age groups $(\mathrm{H}=24.5, \mathrm{p}<0.001)$, the $0-5$ years old group had the highest incidence.

Table 2: Cryptosporidium spp. by age group and sex, twelve year laboratory results, Honduras.

\begin{tabular}{|c|c|c|c|c|c|}
\hline \multirow{3}{*}{ Year } & \multicolumn{5}{|l|}{ Age } \\
\hline & \multicolumn{5}{|c|}{ Number of cases (\%) } \\
\hline & $0-11 \mathrm{~m}$ & $12-23 \mathrm{~m}$ & $24-35 \mathrm{~m}$ & $3-5 y$ & Total \\
\hline 2002 & 3 & 5 & 1 & 3 & 12 \\
\hline 2003 & 9 & 10 & 1 & 4 & 24 \\
\hline 2004 & 2 & 4 & 2 & 1 & 9 \\
\hline 2005 & 4 & 6 & 3 & 0 & 13 \\
\hline 2006 & 1 & 1 & 1 & 0 & 3 \\
\hline 2007 & 0 & 2 & 2 & 3 & 7 \\
\hline 2008 & 1 & 1 & 0 & 0 & 2 \\
\hline 2009 & 0 & 1 & 2 & 2 & 5 \\
\hline 2010 & 1 & 4 & 0 & 2 & 7 \\
\hline 2011 & 0 & 4 & 3 & 2 & 9 \\
\hline 2012 & 5 & 3 & 1 & 2 & 11 \\
\hline 2013 & 3 & 4 & 1 & 4 & 12 \\
\hline Total & $29(25.4)$ & $45(39.5)^{*}$ & $17(15.0)^{*}$ & $23(20.1)$ & $114(56.4)$ \\
\hline
\end{tabular}

Table 3: Percentage Cryptosporidium spp. Infection among children 0 to 5 years old, Honduras.

Cystoisospora belli infections presented a very different picture than Cryptosporidium infections; they occurred mainly among individuals 21 years old and older (81.6\%), and in 19 individuals the infection persisted for longer periods. For $C$. belli cases, the Post hoc Dun test established significant difference between groups 0 to 5 years old with $>21$ years old and between 6 to 20 years old and $>21$ years old $(\mathrm{H}=22.17, \mathrm{p}=0.001)$. Leukocytes, Charcot-Leyden crystals and mucus were additionally recognized in $23.8 \%, 15.0 \%$ and $26.6 \%$ of the $109 C$. belli cases. A statistical difference was found between the presence of mucus and $C$. belli infections $(29 / 109,26.6 \%)$ and between the presence of Entamoeba coli cysts and Cryptosporidium infections, $7 / 202,3.5 \%\left(\mathrm{x}^{2}=23.850, \mathrm{p}=0.008\right)$ (Table 5).

No statistical difference was found between male and female infection with either apicomplexan parasite. Nineteen (13.5\%) out of 109 individuals with cystoisosporiasis (Table 6) had positive MAF on multiple occasions during repeated stool examinations. Oocyte excretion persisted, in a few cases even after a year of primary infection diagnosis. Of those cases, two were adolescents, one was a 20 year old, eight were females. Consulting with the Chief of the Services for Integral Attention (SAI), who attends patients infected with the human acquired immunodeficiency virus (HIV), the drug used to treat $C$. belli infections is trimetroprim sulfametoxazol (TMS); however, we do not have clinical details for each patient's treatment frequency and duration. 
Page 5 of 9

\begin{tabular}{|c|c|c|c|c|c|c|c|c|}
\hline \multirow[b]{2}{*}{ Year } & \multirow{2}{*}{$\begin{array}{l}\text { Total } \\
\text { Cases } \\
\text { (\%) }\end{array}$} & \multirow{2}{*}{$\begin{array}{l}\text { Masc } \\
\text { IFem }\end{array}$} & \multicolumn{6}{|c|}{ Number of cases by age groups (\%) } \\
\hline & & & $\begin{array}{l}\text { 12-23 } \\
\mathrm{m}\end{array}$ & $\begin{array}{l}24-35 \\
\mathrm{~m}\end{array}$ & $3-5 y$ & $\begin{array}{l}6-10 \\
y\end{array}$ & $\begin{array}{l}11-2 \\
0 y\end{array}$ & $\begin{array}{l}>21 \\
y\end{array}$ \\
\hline $2002^{*}$ & $\begin{array}{l}22 \\
(20.2)\end{array}$ & $15 / 7$ & & 0 & 1 & 2 & 1 & 18 \\
\hline 2003 & $\begin{array}{l}15 \\
(13.8)\end{array}$ & $4 / 11$ & 1 & 1 & 0 & 1 & 2 & 10 \\
\hline 2004 & $\begin{array}{l}12 \\
(11.0)\end{array}$ & $6 / 6$ & & 0 & 0 & 0 & 0 & 12 \\
\hline 2005 & $8(7.3)$ & $2 / 6$ & & 0 & 1 & 1 & 0 & 6 \\
\hline 2006 & $3(2.7)$ & $1 / 2$ & & 0 & 0 & 0 & 0 & $2+$ \\
\hline 2007 & $7(6.4)$ & $3 / 4$ & & 0 & 0 & 0 & 1 & 6 \\
\hline $2008^{*}$ & $\begin{array}{l}17(15 . \\
6)\end{array}$ & $12 / 5$ & & 0 & 0 & 0 & 1 & 16 \\
\hline 2009 & $5(4.6)$ & $4 / 1$ & & 0 & 0 & 0 & 1 & 4 \\
\hline 2010 & $8(7.3)$ & $6 / 2$ & 1 & 0 & 0 & 0 & 1 & 6 \\
\hline 2011 & $2(1.8)$ & $1 / 1$ & & 0 & 1 & 0 & 0 & 1 \\
\hline 2012 & $5(4.6)$ & $3 / 2$ & & 0 & 1 & 0 & 1 & 3 \\
\hline 2013 & $5(4.6)$ & $5 / 0$ & & 0 & 0 & 0 & 1 & 4 \\
\hline $\begin{array}{l}\text { Totals } \\
\text { (\%) }\end{array}$ & $\begin{array}{l}109 \\
(0.8)\end{array}$ & $\begin{array}{l}53 / 56 \\
(48.6 / 51 . \\
4)\end{array}$ & $\begin{array}{l}2 \\
(1.8 \%)\end{array}$ & $\begin{array}{l}1 \\
(0.9 \%)\end{array}$ & $\begin{array}{l}4 \\
(3.7 \%)\end{array}$ & $\begin{array}{l}4 \\
(3.7 \% \\
1\end{array}$ & $\begin{array}{l}9 \\
(8.3 \\
\%)\end{array}$ & $\begin{array}{l}89 \\
(81 . \\
60 \% \\
)\end{array}$ \\
\hline
\end{tabular}

more information on the remaining ten patients with cystoisosporiasis from the children and adolescent group.

\begin{tabular}{|l|l|l|}
\hline Parasites \& commensals & C. spp (\%) (n=201) & C. belli (\%) (n=109) \\
\hline Parasites & & \\
\hline S. stercoralis & $9(4.5)$ & $6(5.5)$ \\
\hline G. duodenalis & $5(2.5)$ & $1(0.9)$ \\
\hline C. cayetanensis & $1(0.5)$ & $2(1.8)$ \\
\hline B. coli & $1(0.5)$ & 0 \\
\hline A.lumbricoides & $2(1.0)$ & 0 \\
\hline T. trichiura & $4(2.0)$ & $2(1.8)$ \\
\hline Blastocystis spp. & $13(6.5)$ & $9(8.2)$ \\
\hline E. coli & $7(3.5)^{*}$ & 0 \\
\hline E. nana & $3(1.5)$ & 0 \\
\hline I. bütschlii & $5(2.5)$ & 0 \\
\hline $\begin{array}{l}\text { Abbreviations: C=Cryptosporidium spp.; } \mathrm{n}=\text { =number } \\
\text { (Association analysis showed significant difference between E. coli and C. spp. }\end{array}$ \\
\hline
\end{tabular}

Table 5: Frequency distribution of mixed parasitic infections diagnosed during a twelve year period.

\section{Discussion}

Abbreviations: $m=$ month old; $y=y e a r s$ old; Masc=masculine; Fem=feminine; "Association analysis found significant differences between cases and year in 2002 and 2008 , with 21 and 18 cases, respectively $\left(x^{2}=60.465, p<0.001\right)$; +one case no age registered.

Table 4: Frequency of distribution of total Cystoisospora belli cases by sex and age groups, twelve years laboratory data, Honduras.

One adolescent with leukemia and $C$. belli oocysts in stools, excreted oocysts over more than one year, and the infection did not respond to repeated TMS treatment. He was cured of the leukemia, but the $C$. belli infection persisted for an unknown length of time.

Fifteen concurrent Strongyloides infections were diagnosed, six adult cases each in Cryptosporidium and C. belli infections; three remaining Strongyloides cases were found in three children ages 12, 14, and 15 months old, with cryptosporidiasis (Table 5). It was not possible to characterize the diarrhea in children or adults due to the type of study. According to which ward submitted the stool samples, it was probable that nine individuals in the age group 20 years old or younger and infected either with Cryptosporidium (6/128, 4.7\%) or $C$. belli $(3 / 20,15.0 \%)$ were malignancy patients; their ages ranging from 15 months to 10 years old. It was possible to further identify an underlying medical condition in seven additional patients in that same age group 0 to 20 years old and infected with $C$. belli oocysts: four patients aged 6, 7, 13 and 17 years old had AIDS; two patients 1.5 and 17 years old, were renal insufficiency patients, and a 13 years old adolescent had an endocrine problem. Thus, $50 \%$ of 20 patients with a cystoisosporiasis superimposed infection consulted for a debilitating, probably immune-compromising health issue. We could obtain no

In developing countries where field research projects in parasitology are scarce or nonexistent, the data generated by a diagnostic laboratory with continuously trained laboratory personnel, supervised by specialists in the field, can have a role in providing important information. In the list provided by the World Health Organization (WHO) for rapid data collection for a situation analysis [17], hospital records represent useful information, obtained at low cost. In our case, the laboratory registry book has been filed by year since 1990 and kept under key for perusal when requested by professionals exclusively. The protocols used in the PS for stool, blood and other patient derived products are evidence based, patient centered, with timely communication of results to the attending physicians. Because the results presented here are from patients seeking care at this medical facility, and not from field or community based studies, there are limitations in their interpretation, a fact to keep in mind.

It has been documented that in developing countries, infection with Cryptosporidium oocysts occurs at a very young age. When serologically tested with IgG cryptosporidial antibodies, $57.5 \%$ of 610 children in rural Anhui, China and more than $90 \%$ of 40 children in impoverished areas of Fortaleza, Brazil tested positive early in age, as compared with $16.9 \%$ of 172 children and young adults in Virginia, USA [18]. It is now recognized that diarrhea in children caused by Cryptosporidium accounts for about $20 \%$ in developing countries, with a lower percentage of episodes (9\%) in industrialized ones [19]. More recently, results of the Global Enteric Multicenter Study (GEMS) in which 9,439 enrolled children and 13,129 controls participated, showed Cryptosporidium only second to rotavirus diarrhea in infants 0 to 11 months old, and the second and third leading cause of moderate to severe diarrhea in infants 0 to 11 months and in toddlers 12 to 23 months, respectively [3]. It is not clear whether the parasite 
Citation: Kaminsky RG, Garcia SZR (2017) Update of Human Infections Caused by Cryptosporidium spp. and Cystoisospora belli, Honduras.

Page 6 of 9

remains silent in the intestinal cells for longer periods or infections are acquired constantly from a contaminated environment. One study in asymptomatic Aymara children 5 to 19 years old in Bolivia using a modified kinyoun stain resulted in $31.9 \%$ asymptomatic Cryptosporidium infection, with highest prevalence (33.3\% to $44.4 \%)$ among participants between five and fourteen years old [20]. Another study in Nicaragua utilizing staining and molecular characterization found $35.7 \%$ cryptosporidiosis without diarrhea in children 4 to 15 years old, with highest percentage parasitation (53.3\%) in the age group 13 to 15 years old [21]. The lack of clinical manifestations in older children has been proposed as the development of immunity following frequent exposure to oocysts from the environment [22]. The studies from Bolivia and Nicaragua were conducted in the community, and in the Nicaraguan one, more sensitive molecular techniques were applied for Cryptosporidium identification and species differentiation. We cannot determine the etiology of the diarrhea symptoms among our study population since no other bacterial or virus results were at hand. In Honduras, it would be of interest to further explore the role of Cryptosporidium infection in diarrheal disease, its persistence, and speciation of that parasite in asymptomatic and symptomatic individuals of all ages in the community.

\begin{tabular}{|c|c|c|c|c|c|c|c|c|c|c|c|c|}
\hline \multirow[b]{2}{*}{ Pt\# } & \multicolumn{12}{|l|}{ Year } \\
\hline & 2 & 3 & 4 & 5 & 6 & 7 & 8 & 9 & 10 & 11 & 12 & 13 \\
\hline 195 & $\mathrm{Jn}, \mathrm{Sp}$ & & & & & & & & & & & \\
\hline 676 & My, Ag & & & & & & & & & & & \\
\hline 799 & & $\mathrm{Fb}-\mathrm{My}$ & & & & & & & & & & \\
\hline 977 & & & $\mathrm{Sp}$ & $\mathrm{Sp}$ & & & & & & & & \\
\hline 261 & & & J & $\mathrm{Ag}, \mathrm{Sp}$ & & & & & & & & \\
\hline 970 & & & & & & $J n$ & & $\mathrm{Jr}$ & & & & \\
\hline 819 & & & & & & & My, Jn & $\mathrm{Jr}, \mathrm{Mr}, \mathrm{Ap}, \mathrm{Jn}$ & & & & \\
\hline 340 & & & & & & & My & $\mathrm{Jr}$ & & & & \\
\hline 758 & & & & & & $\mathrm{Jr}$, Ot & & & & & & \\
\hline 257 & & & & & & & & & $\mathrm{Jr}, \mathrm{Jl}$ & & & \\
\hline 871 & & & & & & & & & & $\mathrm{Ag}$ & ال & $\mathrm{Ag}$ \\
\hline 252 & & & & & & & & Mc & & J & Ap & \\
\hline 687 & & & & & & & Mr-Jn & & & & & \\
\hline 140 & & & & & & & $\mathrm{Jn}-\mathrm{Ag}$ & $\mathrm{Nv}, \mathrm{Dc}$ & & & & \\
\hline 691 & & & & & & & & Nv & & $\mathrm{Ag}$ & & \\
\hline 196 & & & & & & & & $\begin{array}{l}\mathrm{Jl}, \mathrm{Ot}, \\
\mathrm{Nv}\end{array}$ & & & & \\
\hline 611 & & & & & & & & & Ap, Jl & & & \\
\hline 41 & & & & & & & & & $\mathrm{Ap}, \mathrm{Ag}$ & & & \\
\hline 506 & & & & & & & & & & & $\mathrm{Sp}, \mathrm{Nv}$ & $\begin{array}{l}\text { All } \\
\text { year }\end{array}$ \\
\hline
\end{tabular}

Table 6: Distribution of cystoisosporiasis patients by year with repeat oocyte positive stool exams.

The data retrieved in this study did not provide any indication for the type of diarrheal illness in children nor on the nutritional status of the individual submitting the stool sample. However, to offer some point of reference, a previous local study on hospital children with cryptosporidiasis infection indicated that only 9 of 53 (18.8\%) infected children were eutrophic; in 23/53 (43.2) of the cases the diarrhea lasted from 8 to more than 20 days; $32 \%$ experienced between 10 to more than 20 daily stool depositions [23]. We could assume that mothers 
who look for assistance at the UH may do so as last resource when home medication fails or the child experiences worsening diarrhea. While this aspect should be a subject for further research in Honduras, the point we would like to make is that Cryptosporidium infection can lead to persistent diarrhea and as a consequence worsen malnutrition; when the infection is acquired during the first two years of life it can be significantly associated with diarrhea [2], and early cryptosporidiasis can in turn be associated with impaired fitness later in life as demonstrated in children who were followed from birth until 4-7 years later [24,25]. Moreover, in a four year prospective study in 189 children with persistent diarrhea in northeastern Brazil, infection with species of Cryptosporidium was associated with increase in diarrhea burdens and growth faltering [26]. This lasting adverse effect was clearly demonstrated in Peruvian children aged 0 to 5 months who acquired Cryptosporidium infection; catch-up growth did not occur and one year after the infection, those previously infected were $0.95 \mathrm{~cm}$ shorter that same age, non -infected infants. In children infected at an older age, catch up growth after one year occurred slower than in controls [27]. According to data from the United Nations World Food Program (2012), from a total population of 975,000 children 0 to 59 months old in Honduras, $23 \%$ were stunted, with a stunting rate of $34 \%$ in rural areas; one in every four child suffered from malnutrition. We have no data that indicates to what degree intestinal cryptosporidiasis, persistent diarrhea and malnutrition interact and contribute, if at all, to the prevalence of poor nutritional status or stunting in children in Honduras. Serious efforts ought to be considered during the community implementation of nutritional programs to investigate the interaction of these and other parasites in the nutritional state of children.

Patients 21 years or older make up another age group diagnosed infected with these apicomplexan parasites in this retrospective analysis; we suspect them to be infected with the human immunodeficiency virus (HIV/AIDS). However, we do not possess concrete information on the underlying disease diagnosis of this particular group. It is now widely accepted that because of HIV infection undermining the immune system of the host, it facilitates the establishment of opportunistic intestinal infections such as Cryptosporidium, C. belli, S. stercoralis and others. In fact, prevalence of such parasitic infections in the HIV/AIDS population is significantly higher than in HIV/AIDS negative individuals. [12,28,29]. It has been reported that immunocompromised patients with diarrhea and CD4 T-cell counts $<200 / \mathrm{mm}^{3}$ or less, may suffer from cryptosporidiasis or cystoisosporiasis. The first reports in HIV-positive individuals with diarrhea in Cameroon indicated up to $48 \%$ cryptosporidiasis, as opposed to $5 \%$ in HIV-positive controls without diarrhea. One hundred and forty two AIDS patients in Honduras with CD4 T-cell counts $<200 / \mathrm{mm}^{3}$ and chronic diarrhea lasting a range of 15 to 545 days were found infected with C. belli (6.3\%), S. stercoralis (9.4\%), and Cryptosporidium (17\%); the association of CD4 counts and intestinal apicomplexa was statistically significant [30]. Since that study overlapped with three years (2003-2005) of our observations, some of those patients may be part of this report. Similar associations were found in HIV infected patients in Venezuela and India, with $14 \%$ and $26.1 \%$ cystoisosporiasis, respectively, and low CD4 counts [6,31]. However, and for reasons not explained, $C$. belli used to be a common finding in Chile before the AIDS pandemic (1952-1976), in community or family outbreaks, with a total of 1,170 reported cases, frequent during the autumn months and mainly in adults [32]. It is assumed that Cryptosporidium does not represent a special threat to patients with malignancies, except for leukemia, where the infection can be severe [33]. On the other hand, many case reports of cystoisosporiasis come from patients with different types of malignancies [34-36]. Moreover, as this analysis showed, in 50\% of patients $<20$ years old, $C$. belli infection was superimposed to an underlying illness. We have no data on the type of malignancy in the nine children found infected with either $C$. belli or Cryptosporidium; therefore, further studies are necessary in Honduras to define risk factors for cystoisosporiasis and cryptosporidiasis in patients with malignancies and to better determine diagnostic protocols useful for the detection of these intestinal parasites, thus benefiting both the patient and the attending clinician.

Identification of these intestinal apicomplexa species requires laboratory implementation of methods that at a minimum facilitate visual recognition of oocysts, although not speciation in the case of Cryptosporidium, such as through staining techniques with acid fast carbolfuchsin of previously fixed stool smears. In resource poor countries methods using immunofluorescence or molecular biology techniques cannot be applied for routine purposes due to their high costs both in equipment and specially trained personnel. Routine laboratories in developing countries should at least be able to implement a modified acid fast method, alone or together with concentration techniques. For cases of child diarrhea, laboratories ought to have in place a uniform protocol for stool examination that includes oocyst staining techniques. To our knowledge, the PS of the $\mathrm{UH}$ is the only laboratory in the country to have in place a protocol to routinely diagnose intestinal apicomplexa infections. The capacity to diagnose parasitic infections in Honduras was found inadequate in $85.7 \%$ of 35 public and private laboratories in Tegucigalpa; less than $12 \%$ performed different coproparasitologic techniques necessary for the accurate diagnosis of helminth and protozoa reproductive products [37]. This lack of reliable diagnosis capacity represents a major barrier in the crucial interactions between doctor and patient for effective treatment of potential intestinal parasitic infections, in the conduction of reliable surveys such as those mentioned for nutritional programs, and in supporting national initiatives in the control of parasitic infections, and makes a strong case for the data presented in this study. Children between 0 to 5 years old and immunocompromised patients including HIV/AIDS and patients with malignancies should be screened routinely for parasites, or at a minimum, when presenting with diarrhea, with minimum inclusion of a Ziehl-Neelsen modified acid fast stain and a Baermann method, in order to benefit of appropriate management strategies and improvement in their general wellbeing.

In conclusion, this retrospective review comprising a twelve year span of hospital laboratory data and supported by statistical analysis has revealed the importance of Cryptosporidium spp. as an intestinal pathogen in children $<5$ years old. On the other hand, infected adults were probably immunocompromised. Cystoisospora belli infections were diagnosed among adult patients, primarily but not solely those with AIDS; there were very few cases in children and adolescents, most of them with an underlying compromising disease. It is imperative that health personnel in Honduras be aware of these parasitic diseases and realize the urgent need for a vigorous teaching program in formal parasitology, associated with strengthening the capacity of laboratory personnel in accurate, reliable diagnoses of parasitic infections. Clinicians have the responsibility to request diagnostic laboratory tests designed for these apicomplexa and other parasitic infections. 


\section{Conflict of Interest}

The authors declare no conflict of interest.

\section{Authors Contributions}

RGK conceived and designed the study protocol, and wrote the manuscript; SRG analyzed the data and designed the figure, revised and approved the manuscript; both modified the revised version and agreed on its presentation and contents.

\section{Financing Support}

Besides regular salary, this investigation did not receive any financial support from any institution or organization and was conducted as part of research responsibilities for RGK at the School of Medical Sciences, Department of Pediatric, National Autonomous University of Honduras.

\section{Acknowledgements}

Fifth year medical students Jandy Flores, Alejandro Medina and Nicolle Ruiz participated in the study phase related to data retrieval for Cystoisospora belli and presented preliminary results at a national scientific congress. The authors wish to acknowledge the National Medical Library personnel for the excellent assistance in reference searching and recognize and thank the Parasitology Service personnel for their accurate parasitology diagnostic capacity and collaboration.

\section{References}

1. Rossle NF, Latif B (2013) Cryptosporidiosis as a threatening health problem: a review. Asian Pacific J Trop Biomed 3: 916-924.

2. Shirley DA, Moonah S, Kotlof K (2012) Burden of disease from cryptosporidiosis. Curr Op Infect Dis 25: 555-563.

3. Kotloff KL, Nataro JP, Blackwelder WC, Nasrin D, Farag TH, et al. (2013) Burden and aetiology of diarrhoeal disease in infants and young children in developing countries (the Global Enteric Multicenter Study, GEMS): a prospective, case-control study. Lancet 382: 209-222.

4. O'Connor RM, Shaffie R, Kang G, Ward HD (2011) Cryptosporidiosis in patients with HIV/AIDS. AIDS 25: 549-560.

5. Forthal DN, Guess SS (1984) Isospora belli enteritis in three homosexual men. Am J Trop Med Hyg 33: 1060-1064.

6. Certad G, Arenas-Pinto A, Pocaterra L, Ferrara G, Castro J, et al. (2003) Isosporiasis in Venezuelan adults infected with the human immunodeficiency virus: clinical characterization. Am J Trop Med Hyg 69: 217-222.

7. Boyles TH, Black J, Meintjes G, Mendelson M (2012) Failure to eradicate Isospora belli diarrhoea despite immune reconstitution in adults with HIV - A Case Series. PLoS ONE 8: e42844

8. Girón SJO, Molina IB, Turcios-Ruiz RM, Mejia QCE, Amendola LM, et al. (2006) Burden of diarrhea among children in Honduras, 2000-2004 estimates of the role of rotavirus. Rev Panam Salud Pbl 20: 377-384.

9. Anonymus. Sexually Transmitted Diseases/AIDS Department, Ministry of Public Health, Honduras.

10. Kaminsky RG (1999) Intestinal parasites in different populations in Honduras. III. Intestinal parasite prevalence in HIV/AIDS patients. Rev Med Hondur 67: 235-242.

11. Kaminsky RG, Stovall ME, Mayer ML, Martin AD, Bowers L, et al. (2007) Intestinal microsporidia in AIDS patients in Honduras. Rev Med Hondur 75: 116-123.

12. Kaminsky RG (2002) Epidemiologic comparison among intestinal apicomplexa infections in a hospital population, Honduras. Rev Med Hondur 70: 164-172.
13. Kaminsky RG, Reyes-García S, Zambrano LI (2016) Unsuspected Strongyloides stercoralis infection in hospital patients with comorbidity in need of proper management. BMC Infect Dis 16: 98-105.

14. Kaminsky RG, Lagos J, Raudales Santos G, Urrutia S (2016) Marked seasonality of Cyclospora cayetanensis infections: ten-year observation of hospital cases, Honduras. BMC Infect Dis 16: 66-74.

15. Ash L, Orihel T (1987) Parasites: a guide to laboratory procedures and identification. ASCP PRESS, American Society of Clinical Pathologists, Chicago, USA.

16. García L, Bruckner D (1993) Diagnostic Medical Parasitology. American Society for Microbiology, 2nd Edition, Washington DC, USA.

17. Montresor A, Crompton DWT, Gyorkos TW, Savioli L (2002) Helminth control in school-age children. A guide for managers of control programmes. World Health Organization, Geneva, Switzerland.

18. Zu SX, Li JF, Barrett LJ, Fayer R, Zhu SY, et al. (1994) Seroepidemiologic study of Cryptosporidium infection in children from rural communities of Anhui, China. Am J Trop Med Hyg 51: 1-10.

19. Fletcher SM, Stark D, Harkness J, Ellisa J (2012) Enteric Protozoa in the Developed World: a Public Health Perspective. Clin Microbiol Rev 25: 420-449.

20. Esteban JG, Aguirre C, Flores A, Strauss W, Angles R, et al. (1998) High Cryptosporidium prevalences in healthy Aymara children from the northern Bolivian altiplano. Am J Trop Med Hyg 58: 50-55.

21. Muñoz-Antoli C, Pavón A, Marcilla A, Toledo R, Esteban JG (2011) Prevalence and molecular characterization of Cryptosporidium in school children from department of Rio San Juan (Nicaragua). Trop Biomed 28: 40-47.

22. Mor SM, Tzipori S (2008) Cryptosporidiosis in children in sub-Saharan Africa: a lingering challenge. Clin Infect Dis 47: 915-921.

23. Alger J Cryptosporidium prevalence in hospitalized patients 0 to 14 years old with diarrheic syndrome, University Hospital (1986) Thesis, Medical Doctor and Surgery Degree, Honduras National Autonomous University. 618.923427 A39. Honduras.

24. Moore SR, Lima NL, Soares AM, Oriá RB, Pinkerton RC, et al. (2010) Prolonged episodes of acute diarrhea reduce growth and increased risk of persistent diarrhea in children. Gastroenterol 139: 1156-1164.

25. Guerrant DI, Moore SR, Lima AAM, Patrick PD, Schorling JB, et al. (1999) Association of early childhood diarrhea and cryptosporidiosis with impaired physical fitness and cognitive function four-seven years later in a poor urban community in Northeast Brazil. Am J Trop Med Hyg 61: 707-713.

26. Lima AAM, Moore SR, Barboza Jr MS, Soares AM, Schleupner MA, et al. (2000) Persistent diarrhea signals a critical period of increased diarrhea burdens and nutritional shortfalls: A prospective cohort study among children in Northeastern Brazil. J Infec Dis 181: 1643-1651.

27. Checkley W, Epstein LD, Gilman RH, Black RE, Cabrera L, et al. (1998) Effects of Cryptosporidium parvum infection in Peruvian children: growth faltering and subsequent catch-up growth. Am J Epidem 148: 497-506.

28. Pinlaor S, Mootsikapun P, Pinlaor P, Pipitgool V, Tuangnadee R (2005) Detection of opportunistic and non-opportunistic intestinal parasites and liver flukes in HIV-positive and HIV negative subjects. Southeast Asian J Trop Med PubHealth 36: 841-845.

29. Nkenfou C, Tafou Nana C, Khan Payne V (2013) Intestinal parasitic infections in HIV infected and non- infected patients in a low HIV prevalence region, West-Cameroon. PLoS One 8: e57914.

30. Sorto R, Bú E (2003) Clinical and parasitological profile of HIV/AIDS patients treated at the University Hospital during 2003-2005 period. Rev Med Hondur 74: 69-76.

31. Vignesh R, Balakrishnan P, Shankar EM, Murugavel KG, Hanas S, et al. (2007) Short report: high proportion of isosporiasis among HIV-infected patients with diarrhea in southern India. Am J Trop Med Hyg 77: 823-824. 
Citation: Kaminsky RG, Garcia SZR (2017) Update of Human Infections Caused by Cryptosporidium spp. and Cystoisospora belli, Honduras.

Page 9 of 9

32. Neira PO, Barthel EM, Wilson GL , Muñoz NS (2010) Isospora belli infection in HIV positive patients. Presentation of two cases and literature review. Rev Chilena Infect 27:219-227.

33. Hassanein SM, Abd-El-Latif MM, Hassanin OM, Abd-El-Latif M, Ramadan NI (2012) Cryptosporidium gastroenteritis in Egyptian children with acute lymphoblastic leukemia: magnitude of the problem. Infect 40: 279-284.

34. Meamar AR, Rezaian M, Zare-Mirzaei A, Zahabiun F, Faghihi AH, et al. (2009) Severe diarrea due to Isospora belli in a patient with thymoma. J Microbiol Immunol Infect 42: 526-5292.

35. Sanad MM, Thagfan FA, Al Olayan EM, Almagren A, Al Hammaad A, et al. (2014) Opportunistic coccidia parasites among Saudi cáncer patients presentin with diarrhea: prevalence and immune status. Res J Parasitol 9: 55-63.

36. Ud Din N, Torka P, Hutchison RE, Riddell SW, Wright J, et al. (2012) Severe Isospora (Cystoisospora) belli diarrhea preceding the diagnosis of human T-cell-leukemia-virus-1-associated T-cell lymphoma. Case Rep Infect Dis 640104 .

37. García JA, López W, Alger J, Matute ML, Kaminsky RG (2014) Parasitologic diagnosis in public and private laboratories in Tegucigalpa, Honduras: capacity of response? Rev Med Hondur 82: 148-154. 